\title{
LOS NUEVOS RUMBOS DEL MERCOSUR. El CAMBIO DE MODELO Y LAS CONSECUENCIAS DE LA CRISIS BRASILENA
}

\author{
NEW DIRECTIONS FOR MERCOSUR. \\ A CHANGE IN MODEL AND THE CONSEQUENCES \\ OF THE BRAZILIAN CRISIS
}

\section{LA NOUVELLE ORIENTATION DU MERCOSUR. LE CHANGEMENT DE MODĖLE AU BRÉSIL ET LES CONSÉQUENCES DE SA CRISE}

\author{
Gerardo Caetano \\ Universidad de la República \\ gcaetano50@gmail.com
}

Resumen: Este artículo examina la encrucijada actual del Mercosur y las consecuencias que en ésta tuvieron los cambios políticos de los últimos años en Brasil, por lo que toca a un cambio de paradigma integracionista mediante la adopción de perfiles de corte más "liberal-comercialista". Las preguntas de investigación que se plantean en el artículo son dos. ¿Hasta qué punto y en qué sentido los derroteros más recientes del bloque Mercosur implican un cambio sustantivo de su "modelo" integracionista? ¿Cuánto ha afectado en esa deriva del bloque regional el cambio político efectivizado a partir de 2016 en Brasil? Para tales efectos, se sigue en el artículo la siguiente ruta de análisis: 1) una inscripción del texto propuesto en las discusiones académicas más recientes sobre ambos temas; 2) un examen necesariamente sumario y provisorio acerca del giro producido en la política exterior de Brasil en los últimos años; 3) una evaluación sobre las consecuencias de esos cambios en Brasil respecto a la evolución del proceso MERcosur en el corto y mediano plazos.

Palabras clave: Mercosur; Brasil, integración; regionalismo; política exterior.

ABSTRACT: This article examines the current crossroads facing MERCOSUR and the consequences of the recent political changes in Brazil, in terms of a shift from the integrationist paradigm to the adoption of a more "commercial-libe- 
ralist" profile. Two research questions are posed in the article. To what extent do the most recent directions taken by the MERCOSUR bloc imply a real change to its integrationist model? How much has the political change effected since 2016 in Brazil affected the course of the regional bloc? To answer these questions, the article undertakes the following analysis: 1) an engagement with the most recent academic discussions on both subjects; 2) a necessarily brief and provisional examination of the turn taken by Brazil's foreign policy in recent years; 3) an evaluation of the consequences of these changes in Brazil for the evolution of the MERCOSUR process in the short and medium terms.

Keywords: Mercosur; Brazil, integration; regionalism; foreign policy.

\section{Traducción de Gonzalo Celorio Morayta}

RÉSUMÉ: L'article examine l'impasse où se trouve à présent le MERCOSUR et les conséquences, pour celui-ci, des changements politiques au Brésil le long des dernières années, qui auraient favorisé la substitution du modèle intégrationniste par un autre bien plus "commercialiste-libéral". Notre démarche analytique est guidée par deux questions principales: jusqu'à quel point l'évolution récente du MERCOSUR signifie-t-elle une vraie altération du modèle intégrationniste, et dans quelle mesure peut-on l'attribuer aux transformations qui ont eu lieu au Brésil depuis 2016? Pour essayer d'y répondre, notre article considère les débats académiques récents sur ces sujets; il propose ensuite un résumé des changements qu'a subis la politique étrangère du Brésil au cours des dernières années, et il s'achève sur une évaluation de ce qu'implique le virage brésilien pour le Mercosur, à court et à moyen terme.

Mots clefs: Mercosur; Brésil; intégration; régionalisme; politique étrangère.

Traducción de BERNARDo MABIRE

Fecha de recepción: junio de 2017

Fecha de aceptación: julio de 2018 
$\mathrm{E}$ L cambio de paradigmas en los procesos de integración y de regionalismo ${ }^{1}$ hace tiempo que viene consolidándose en distintas partes del mundo. En América Latina, por motivos que van desde lo político a lo económico comercial, una multiplicidad de procesos, aunque desde distintos formatos y objetivos, parece dar cuenta de ese cambio. En ese contexto y como un ejemplo singular, el MERCosur ha sido uno de los bloques latinoamericanos que ha apostado de manera más persistente a los objetivos -más en el discurso que en la práctica- de construir una unión aduanera y de consolidar un espacio de convergencia política sólida, tanto en lo que tiene que ver con la idea de un espacio de desarrollo compartido, como en la negociación comercial conjunta. En los hechos, sin embargo, el bloque no ha podido avanzar seriamente en esos dos objetivos: en términos efectivos no ha podido alcanzar más que una zona de libre comercio perforada, una unión aduanera muy defectuosa y cada vez más discutida, una agenda externa común paupérrima, así como una convergencia política más retórica que real, situación que en los últimos años se ha profundizado con el cambio de ciclo político en el Cono Sur. Ha sido uno de los casos más referidos como ejemplo de "regionalismo posliberal" o "poshegemónico", según se verá más adelante, pero en ello las evidencias indican que ha habido más retórica que realidad.

A esta situación de déficit general, que ya venía desde hace años, se ha sumado en el último tiempo el colapso de Venezuela y su suspensión como Estado parte del bloque, a lo que habría también que agregar de manera central la grave crisis por la que viene atravesando su socio principal, Brasil, con el hito cercano de la caída del gobierno electo de Dilma Rousseff, en 2016, y el subsiguiente cambio neto de gobierno, liderado por su compañero de fórmula en las elecciones de 2014,

${ }^{1}$ En el presente artículo, los términos integración, regionalismo o regionalización se utilizan como sinónimos, decisión que han tomado también autores como Alberto van Klaveren o Philippe de Lombaerde, entre otros. El autor agradece a Camilo López y a Carlos Luján las aportaciones y sugerencias para este trabajo. 
Michel Temer, devenido no sólo en nuevo presidente, sino también en el líder de un gobierno completamente antagónico, de signo casi opuesto. Con un trámite jurídico y político con graves ilegitimidades de origen, ${ }^{2}$ lo cierto es que el gobierno del país más importante del Mercosur y de América del Sur, sin el respaldo de un nuevo pronunciamiento electoral y en medio de una fortísima impopularidad, ${ }^{3}$ ha variado radicalmente sus políticas públicas y su rumbo general. Uno de los principales ejemplos de ese viraje está configurado por los cambios profundos que se han adoptado en su política exterior durante el último bienio, con sus consecuencias en los rumbos del bloque mercosur. A ello deben sumarse las consecuencias en todo el Continente, pero especialmente en Brasil, de denuncias de corrupción generalizada, que atraviesan todos los partidos y que han suscitado incógnitas y desencantos en vísperas de los futuros procesos electorales. ${ }^{4}$

${ }^{2}$ En otros textos, hemos fundado las razones que a nuestro juicio habilitan caracterizar lo ocurrido en Brasil, en 2016, como un "golpe de Estado blando". En forma muy resumida, centraríamos la fundamentación de este juicio en tres argumentos: 1) durante todo el impeachment no pudo probarse que la presidente Dilma Rousseff hubiera cometido "delito de responsabilidad", como lo requiere la Constitución brasileña; 2) sin la manifestación de la soberanía popular, el nuevo presidente Michel Temer ha venido impulsando un cambio radical de gobierno con políticas en muchos casos antagónicas a las anteriores, propias de un gobierno electo en el 2014 del que fue vicepresidente; 3) la situación emergente, más allá de la continuidad legal, incluye asesinatos políticos y reducción de derechos, medidas que se asemejan a las impuestas por un "Estado de excepción". Situaciones similares de "golpe blando" se han venido dando en otros países latinoamericanos como Haití (2004), Paraguay (2012), Honduras (2009 y 2017), Guatemala (2017), Venezuela (a partir de su deriva autoritaria y en especial desde la crisis político-institucional radicalizada en el último trienio 2016-2018).

${ }^{3}$ Temer ha ostentado, desde que asumió el cargo, los índices de popularidad más bajos de la historia brasileña en lo que atañe al Presidente.

${ }^{4}$ En particular, el acuerdo delictivo en Brasil entre empresas privadas de obra pública (en particular la gigantesca ODEBRECHT) y la petrolera PETROBRAs ha desatado una ola de denuncias y procesos en toda la región, con un fortísimo impacto en varios gobiernos y partidos de signo 
El trabajo propuesto apunta a examinar la encrucijada actual del MERCosur desde la hipótesis de un cambio progresivo de paradigma integracionista, con la adopción de perfiles vinculados en algunos casos con el aceleramiento de transformaciones que ya venían en curso -como los intentos de flexibilización comercial, la discusión de la negociación en bloque y las llamadas "múltiples membresías" de sus Estados miembros-, y en otros con modificaciones más drásticas, como la apertura acelerada frente a mercados extrazona, la confirmación de una estrategia de impulso a acuerdos comerciales con los países desarrollados y la experimentación de rumbos mucho más autónomos por parte de cada uno de los socios del bloque. A partir del registro de ese primer foco general, se pondrá especial atención en el vínculo de ese nuevo derrotero con los cambios operados en el Brasil reciente en lo que atañe a la política exterior, de modo especial a partir de la asunción del presidente Temer en 2016. En este marco, las preguntas de investigación que se plantean en el artículo son dos. ¿Hasta qué punto y en qué sentido los derroteros más recientes del bloque MERCosur implican un cambio sustantivo de su "modelo" integracionista? ¿Cuánto ha influido en esa deriva del bloque regional el cambio político efectivizado a partir de 2016 en Brasil?

Para tales efectos, se sigue en el artículo la siguiente ruta de análisis: 1) una inscripción del análisis propuesto entre las discusiones recientes con respecto de los modelos predominantes de integración en América Latina, tanto en sus dimensiones económico-comerciales, como políticas, con un relevamiento especial de los principales retos y cambios del MERCOSUR en los últimos años; 2) un examen necesariamente sumario y provisorio - dada la incertidumbre de los procesos que se viven en el presente, con las elecciones generales

diverso. En Brasil, las acusaciones cruzan todo el sistema político y han llegado a poner en prisión al otrora presidente Lula en abril de 2018, sometido a varios procesos judiciales por posibles actos de corrupción activa o pasiva. 
en octubre y noviembre de $2018-^{5}$ acerca del giro pronunciado en la política exterior de Brasil, con sus consecuencias en la evolución del bloque en su conjunto; 3) una evaluación sintética de los escenarios previsibles del proceso MERCOSUR en el corto y mediano plazos.

\section{Algunas pistas para analizar EL CASO DEL MERCOSUR}

Los procesos de integración regional han sufrido importantes transformaciones en las últimas décadas. ${ }^{6}$ Las relaciones comerciales entre los Estados difieren en la actualidad de las que se desplegaban en décadas pasadas, cuando estos procesos tenían otras características y se enmarcaban en las definiciones de las teorías clásicas de la integración económica, que diferenciaba al proceso según diferentes niveles. ${ }^{7}$ Imperaban por entonces clasificaciones relacionadas con distintos grados de profundidad según los instrumentos de política comercial definidos por los miembros, como zonas de libre comercio, uniones aduaneras, mercados comunes o uniones económicas.

El proceso de integración más característico de los últimos sesenta años fue el de la Comunidad Económica Europea (CEE), hoy Unión Europea (UE), esquema de integración que -en forma más o menos indirecta- marcó casi todos los procesos latinoamericanos que desde los años 60 tomaron

${ }^{5}$ Pese a su aprisionamiento, que se mantiene mientras escribo este artículo, Lula sigue teniendo un predominio claro en las encuestas, apenas a tres meses de la primera vuelta de octubre.

${ }^{6}$ Algunos de los desarrollos teóricos en este apartado son tributarios de un trabajo del autor en colaboración con I. BARTESAGHI sobre el tema "La agenda externa del Mercosur y las negociaciones con la Unión Europea: ¿la última oportunidad?”, Aldea Mundo. Revista sobre fronteras e integración, 19 (2014), núm. 37, pp. 9-24.

${ }^{7}$ B. A. Balassa, Teoría de la integración económica, México, Biblioteca Uthea de Economía, 1964. 
como referencia ese modelo, más allá de las notorias diferencias en los resultados. Éste fue el caso de la Asociación Latinoamericana de Libre Comercio (hoy ALADI), el Mercado Común Centroamericano (hoy sica), el Pacto Andino (hoy Comunidad Andina), el Mercado Común del Caribe (CARICOM). Si bien se constituyó muchos años después, a partir del Tratado de Asunción de 1991, el Mercado Común del Sur (MERCosur) también fue parte de este fenómeno de emulación, muchas veces implícito, ya que, como todos estos procesos de integración, se inspiró en más de un sentido -aunque a menudo se lo niegue- en la Comunidad Económica Europea. La persistente aspiración de constituir como bloque una unión aduanera resulta una de las primeras evidencias en ese sentido.

Para aclarar algunas de las consideraciones que siguen, es menester identificar cuatro etapas en los procesos de integración económica regional desde la Segunda Posguerra hasta nuestros días: 1) una primera, que se caracteriza por hitos como la creación del General Agreement on Tariffs and Trade (GATT) de 1947 o de la Comunidad Económica Europea (CEE) nacida a partir de la firma del Tratado de Roma de marzo de 1957, así como por acuerdos de tipo profundo en América Latina y Europa, en el marco de lo que Roberto Bouzas et al. han llamado la "etapa de gran diseño";8 2) una segunda, signada por una reformulación de los procesos integracionistas hacia una lógica de mayor apertura con un declive progresivo del multilateralismo y mayores contactos de EE. UU. y de la UE con el resto del mundo; 3) una tercera, caracterizada por un crecimiento exponencial de los acuerdos comerciales bilaterales ("spaghetti bowl"), con formatos menos rígidos que los firmados en décadas anteriores; 4) una cuarta etapa en curso de definición y despliegue, con nuevos cambios en el comercio internacional y en las disciplinas comerciales, creciente importancia de las barreras no arancela-

8 "El Mercosur a 15 años de su creación", Revista Relaciones Internacionales, sección Diálogos, 15 (2006), núm. 30, pp. 3-23. 
rias en la liberalización comercial y de las nuevas disciplinas "omc plus" (normas medioambientales, laborales, propiedad intelectual, compras públicas). Esta etapa, actualmente en curso, aparece hoy con grandes incertidumbres de rumbo, a partir del giro proteccionista de los EE. UU. de Trump, la deriva empantanada de los megaacuerdos (del tipo de los anunciados TTP, TTIP o TISA), la estrategia más heterodoxa de China -con su Regional Comprehensive Economic Partnership (RCEP)-, o los nuevos acuerdos emprendidos por la Unión Europea (como el llamado "CETA" con Canadá), entre otros fenómenos.

En tiempos más recientes, muchos de los mencionados procesos de integración en América Latina han ingresado en situaciones críticas de diversa índole, ${ }^{9}$ lo que ha llevado a situaciones que en algunos casos ponen en riesgo la continuidad efectiva de algunas de esas experiencias de integración. El nuevo escenario emergente desde finales del siglo $\mathrm{xx}$, como ha aseverado Jagdish Bhagwati, ${ }^{10}$ se caracteriza por una progresión de acuerdos comerciales bilaterales, en los que se negocian diferentes cronogramas de desgravación, distintos márgenes de preferencia, regímenes de orígenes distintos, así como otras disposiciones y disciplinas que no son necesariamente coincidentes entre sí, lo que dificulta la armonización internacional.

Como se indica en el cuadro 1, la omc contaba hasta el 2012 con 379 notificaciones que, como puede observarse, eran en su mayoría acuerdos de integración económica y acuerdos de libre comercio, no uniones aduaneras como la que pretendió conformar el MERCOSUR desde la década de los años noventa. Una de las nuevas tendencias del comercio internacional tiene que ver con la interrogación acerca de

${ }^{9}$ El desfibramiento progresivo de la Comunidad Andina de Naciones (CAN) o la inercia actual del mercosur, en lo que se refiere a muchos de sus objetivos originarios (tanto comerciales como políticos), podrían ponerse como ejemplos de esos fenómenos de crisis a que nos referimos.

10 Termites in the Trading System: How Preferential Agreements Undermine Free Trade, Oxford, University Press, 2008. 
quiénes negocian dichos acuerdos, los que ya no involucran necesariamente a Estados vecinos o ubicados en una misma región, con una creciente influencia de las empresas multinacionales. Además de esa nueva lógica de deslocalización, este tipo de acuerdos es cada vez más complejo en las disciplinas negociadas y acompaña las transformaciones que se registran internacionalmente con el impulso del avance tecnológico. También deben tenerse muy en cuenta, por ejemplo, los cambios en la forma de producir. Al respecto, Richard Baldwin ha planteado que una de las diferencias entre los siglos Xx y xxi tiene que ver con el nivel de interacción que se ha alcanzado por los avances tecnológicos (transportes y tecnología), lo que ha permitido la deslocalización de inversiones y el desarrollo de cadenas globales de valor. ${ }^{11}$ También otros autores, como Sanahuja y Comini, han señalado más recientemente la centralidad de esta "reorganización de la producción” global, a partir del nuevo ciclo de innovación tecnológica que acompaña hace tiempo a la "cuarta revolución industrial". ${ }^{12}$

En esa dirección de abandono creciente de los formatos regionalistas que incorporan la propuesta de las uniones aduaneras, los registros indican que desde la década de los noventa se ha venido dando un crecimiento exponencial de acuerdos bilaterales, en lo que algunos autores calificaron en su momento como "nuevo regionalismo". ${ }^{13}$

11 " $21^{\text {st }}$ Century Regionalism: Filling the Gap between $21^{\text {st }}$ Trade and 20"th Century Trade Rules", ssRn, abril de 2011, en https://ssrn.com/abstract $=1869845$.

12 Cf. J. A. Sanahuja, "Posglobalización y ascenso de la extrema derecha: crisis de hegemonía y riesgos sistémicos", Anuario CEIPAZ 2016-2017: Seguridad internacional y democracia: guerras, militarización y fronteras, coord. por M. Mesa, pp. 41-77, y J. A. Sanahuja y N. Comini, "Las nuevas derechas latinoamericanas frente a una globalización en crisis", Nueva Sociedad, 2018, núm. 275, pp. 36-37.

13 S. BAIER et al., "El nuevo regionalismo: causas y consecuencias", Integración Ẽ Comercio, 2007, núm. 26, pp. 9-32. 


\section{CuAdro 1}

Tipo de acuerdos notificados en la OMC $^{\mathrm{a}}$

(Acuerdos en vigor hasta el año 2012)

\begin{tabular}{lcccc}
\hline \multicolumn{1}{c}{ Tipo de acuerdo } & $\begin{array}{c}\text { Clásula de } \\
\text { Habilitación }\end{array}$ & GATS Art. V & $\begin{array}{c}\text { GATT, artículo } \\
\text { XXIV }\end{array}$ & $\begin{array}{c}\text { Gran } \\
\text { total }\end{array}$ \\
\hline $\begin{array}{l}\text { Unión aduanera } \\
\text { Unión aduanera - }\end{array}$ & 8 & & 10 & 18 \\
$\begin{array}{l}\text { Adhesión } \\
\text { Acuerdo de integración } \\
\text { económica }\end{array}$ & 1 & & 7 & 8 \\
$\begin{array}{l}\text { Acuerdo de integración } \\
\text { económica - Adhesión }\end{array}$ & 114 & & 114 \\
$\begin{array}{l}\text { Acuerdo de libre comercio } \\
\text { Acuerdo de libre } \\
\text { comercio - Adhesión }\end{array}$ & 0 & 4 & 207 & 4 \\
$\begin{array}{l}\text { Acuerdo de alcande parcial } \\
\text { Acuerdo de alcance } \\
\text { parcial - Adhesión }\end{array}$ & 14 & & 1 & 1 \\
\hline
\end{tabular}

Fuente: elaboración con base en datos proporcionados por la omc.

${ }^{\text {a }}$ En algunos casos, las uniones aduaneras son notificadas tanto por la Cláusula de Habilitación, como por el Artículo XXIV del GATT, lo que causa algunas duplicaciones.

¿Cuál fue la razón última de ese tránsito más o menos generalizado, que cada vez tensiona más la evolución reciente de los procesos latinoamericanos, en particular la del MERcosur? Algunos autores, como Paul Krugman, advierten a menudo que hay claros indicios de que una de las claves de la respuesta se halla en la política internacional dominante, en particular a partir de las iniciativas desplegadas por los países más poderosos. Otros autores, ante la pregunta de por qué se acuerdan más zonas de libre comercio que uniones aduaneras en los últimos años, ${ }^{14}$ tienden a concluir que en los actuales contextos las primeras son políticamente más viables que las segundas, más allá de los debates ideológicos

${ }^{14}$ G. Facchini et al., "The Customs Union Issue: Why do We Observe so Few of Them?", Journal of International Economics, 90 (2008), núm. 1, pp. 136-147. 
vinculados a los modelos de desarrollo que sustentan -de modo más o menos directo- una u otra opción.

\section{GRÁFICA 1}

Evolución de las notificaciones en la OMC, según el número de acuerdos en vigor hasta el 2012

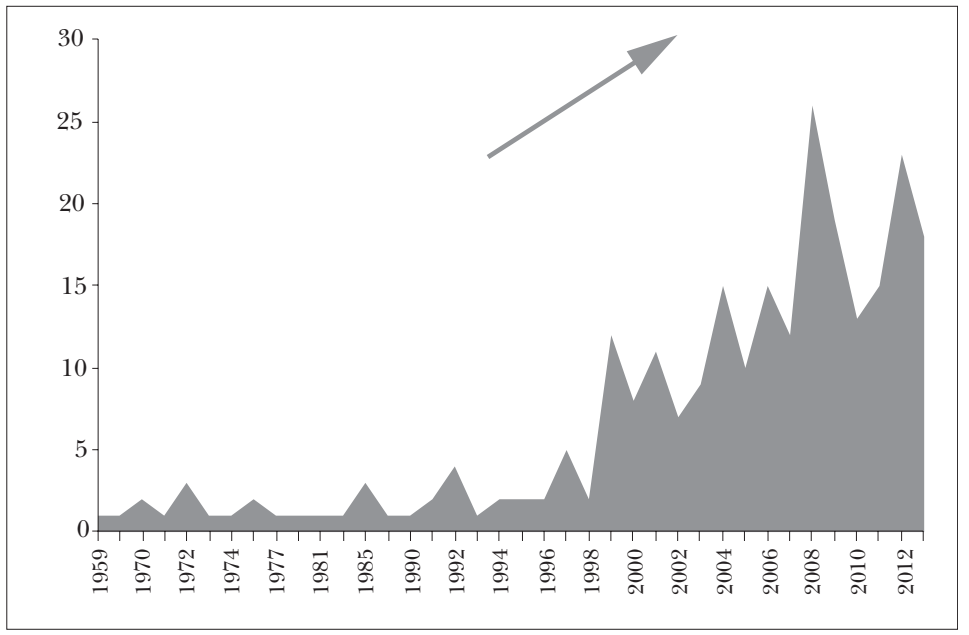

Fuente: elaboración con base en datos de la omc.

Como puede observarse en la gráfica 2, donde figuran todos los ACR notificados al GATT/OMC (1984-2016), a más de los ACR inactivos según el año en que entraron en vigor, las tendencias mencionadas se confirman. En esa misma dirección y con particular significación analítica para el estudio de los regionalismos latinoamericanos, la multidimensionalidad y el pluralismo manifiestos de las políticas de integración regional han provocado una fuerte ampliación de taxonomías y clasificaciones diferentes en el ámbito del regionalismo comparado. ${ }^{15}$

15 Cf. S. Gratius (ed.), MERCosur y NAFTA. Instituciones y mecanismos de decisión en procesos de integración asimétricos, Madrid, Iberoamericana-Ver- 
GrÁficA 2

Evolución de los Acuerdos Regionales de Comercio en el Mundo entre 1948 y 2016

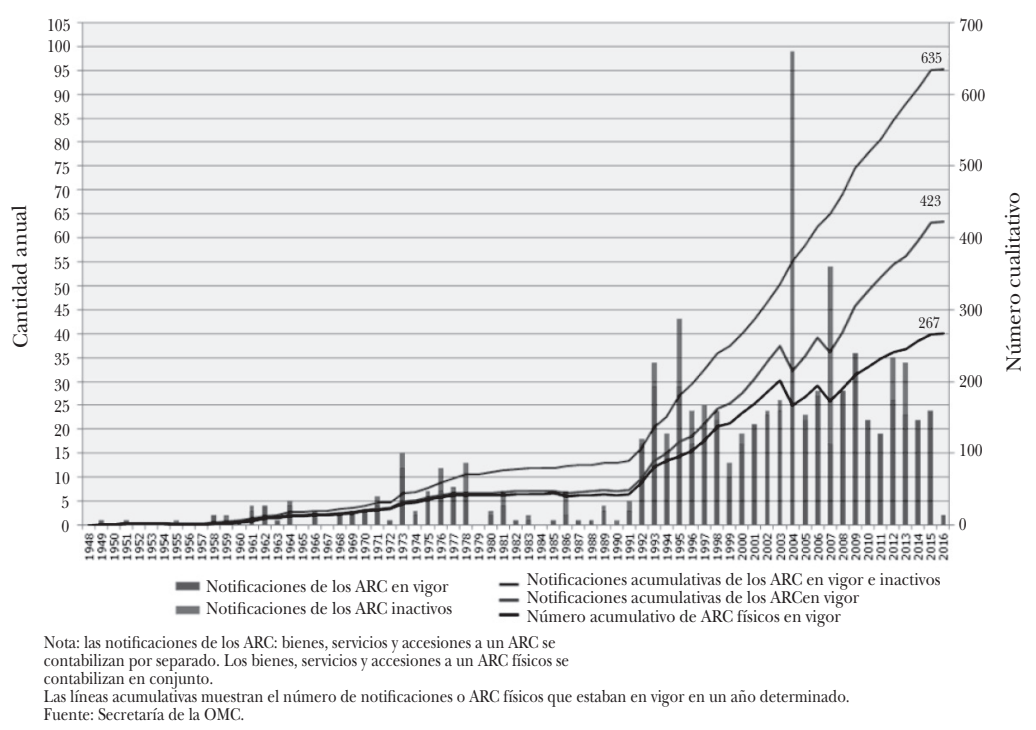

Fuente: Secretaría de la omc.

vuert, 2008; K. HochstetLer, "Multi-Level Governance and Social Movements in Mercosur", ponencia presentada en la 2007 Annual Convention of the American Political Science Association, Chicago, IL, 30 de agosto-2 de septiembre; A. Malamud y P. C. Schmitter, "La experiencia de integración europea y el potencial de integración del Mercosur", Desarrollo Económico. Revista de Ciencias Sociales, 46 (2006), núm. 181, pp. 3-31; M. Mondelli, "Case Studies on Social Dimension in MERCOSUR, ECOWAS and ASEAN", documento de trabajo, Buenos Aires, CLACso, 2015; J. R. Perales, "A Supply-Side Theory of International Economic Institutions for the Mercosur”, en F. Laursen (ed.), Comparative Regional Integration: Theoretical Perspectives, Aldershot, Ashgate, 2003; B. Rosamond, Theories of European Integration, Basingstoke, Macmillan-St. Martin's Press, 2000; y A. Sbragia, "Review Article: Comparative Regionalism: What Might It Be?", Journal of Common Market Studies, 46 (2008), pp. 29-49. 
En estudios recientes, no son pocos los autores que se refieren a la fuerza de estas rediscusiones con respecto de los casos latinoamericanos y sus formatos. Este discutido cambio de modelos se vuelve más fuerte en el caso del MERcosur, cuyos Estados parte no han renunciado al objetivo de constituir una unión aduanera, pero que en los hechos se comportan, y cada vez más, como si hubieran abdicado de esa aspiración. ${ }^{16}$ Andrés Malamud ha señalado lo que sigue a propósito de lo que indica la trayectoria del bloque:

Creado en 1991, es uno de los más notorios miembros de la tercera ola integracionista en las Américas, contemporáneo del TLCAN, pero ubicado en el otro extremo del Continente... Su forma es diferente de la de muchos intentos previos o contemporáneos. Como ha observado Félix Peña, es "un caso de regionalismo abierto en el marco de la Organización Mundial de Comercio"... Sin embargo, el mercosur no ha construido ninguna estructura institucional significativa, sea supranacional o no. Toma sus decisiones mediante mecanismos exclusivamente intergubernamentales, requiriendo unanimidad en todos los casos... El éxito relativo obtenido por el bloque en sus primeros años se debió a una intensa dinámica interpresidencial... Sin embargo, a partir de 1997 el dinamismo del MERCosur comenzó a declinar y la ausencia de instituciones evitó que los avances logrados se afianzaran. Por el contrario, el bloque sufre actualmente un proceso de degradación operativa mal disimulado por el aumento del discurso integracio-

${ }^{16}$ Según el académico mexicano Cassio Luiselli, "uno de los grandes problemas del MERCosur fue justamente el pretender llegara a una Unión Aduanera sin antes haber consolidado las otras etapas de menor complejidad, como fue el caso europeo. El Arancel Externo Común es una tremenda camisa de fuerza, que necesariamente servía mejor a los intereses industriales de la potencia mayor, Brasil. Eso era y es incómodo para Argentina... y para Uruguay y Paraguay, prohibitivo" (Hipótesis para el Mercosur que viene, Montevideo, CEFIR-FESUR, 2014, p. 123). 
nista en lo que se ha dado en llamar un caso de "disonancia cognitiva". ${ }^{17}$

El enfoque de Malamud incorpora en su perspectiva comparativa entre modelos integracionistas la cuestión nada menor del formato institucional de cada bloque y del procedimiento de toma de decisiones. Por su parte, autores como José Antonio Sanahuja y Nicolás Comini, cuyo estudio se ha citado líneas arriba, priorizan en el análisis del cambio de modelos integracionistas en América Latina las consecuencias del "giro liberal frente a una globalización en crisis”, lo que a su juicio promovería en países como Argentina, Brasil o Colombia una "desvinculación progresiva de plataformas integracionistas como la Comunidad de Estados Latinoamericanos y Caribeños (CELAC) o la Unión Sudamericana de Naciones (UNASUR)", asociada con un nuevo "regionalismo uniaxial" orientado al eje económico-comercial y a sus socios correspondientes (EE. UU., UE, Canadá, Corea del Sur, Asociación de Naciones del Sudeste Asiático o Alianza del Pacífico). En el caso específico de Brasil, estos autores observan "un enfoque regionalista" cada vez más "afín a la defensa de la globalización... [con] una integración abierta y transparente compatible con el orden económico global".

A partir de ese destaque especial del eje ideológico y de su impacto sobre los proyectos integracionistas, varios autores han identificado en las últimas décadas la propuesta de un "regionalismo posneoliberal" principalmente en América del Sur, impulsado por los gobiernos progresistas, con algunas características definitorias de su programa:

Primacía de la agenda política y una menor atención de la agenda económica y comercial; el retorno de la agenda de de-

17 A. Malamud, "Conceptos, teorías y debates sobre la integración regional”, Norteamérica. Revista Académica del CISAN-UNAM, 6 (2011), núm. 2, pp. 234-236. 
sarrollo; un mayor papel de los actores estatales; un énfasis mayor en la agenda positiva de la integración; una mayor preocupación por las dimensiones sociales y las asimetrías en cuanto a niveles de desarrollo; mayor preocupación por... la infraestructura regional; más énfasis en la seguridad energética; la búsqueda de fórmulas para promover... la legitimación social de los procesos de integración. ${ }^{18}$

Las discusiones en torno a los límites y alcances efectivos de estas formas de "regionalismo posliberal" (llamado también "poshegemónico") se perfilan en la actualidad como el escenario de un fuerte debate. Desde un balance crítico y a la luz de lo ocurrido en los últimos años, las evidencias parecen inclinarse a fundamentar la opinión que -más allá de logros parciales- ni las convergencias ni mucho menos esta pauta de regionalismo programático "posliberal" pudieron avanzar en los hechos desde esa "afinidad ideológica" tantas veces invocada por los "gobiernos progresistas". Se trató, en todo caso, de proyectos invocados con ambición, pero que luego no pudieron confirmarse. Desde un análisis especialmente

${ }^{18}$ Para profundizar en esta caracterización, cf. A. Serbin et al. (coords.), Anuario de la Integración Regional de América Latina y el Gran Caribe, 2012, núm. 9: El regionalismo "post-liberal" en América Latina y el Caribe: nuevos actores, nuevos temas y nuevos desafíos. En particular, véase J. A. SANAhuja, "Regionalismo «post-liberal» y multilateralismo en Sudamérica", pp. 19-72. Del mismo autor, "Del «regionalismo abierto» al «regionalismo post-liberal». Crisis y cambio en la integración regional en América Latina", Anuario de la Integración Regional de América Latina y el Gran Caribe, 2008-2009, núm. 7, coord. por L. Martínez Alfonso, L. Peña y M. Vazquez, pp. 11-54. Para enfoques críticos respecto de esta caracterización, pueden citarse, como ejemplo, E. Lander, “¿Modelos alternativos de integración? Proyectos neoliberales y resistencias populares", OSAL, 5 (2004), núm. 15, pp. 9-12, y J. Briceño Ruiz, "Hegemonía, poshegemonía, neoliberalismo, posneoliberalismo en los debates sobre el regionalismo en América Latina”, en M. Ardila (ed.), ¿¿Nuevo multilateralismo en América Latina? Concepciones y actores en pugna, Bogotá, Universidad Externado de Colombia, 2016. 
crítico han señalado sobre este particular Daniele Benzi y Marco Nerea que

una selva de adjetivos ha dominado los principales debates para caracterizar el regionalismo latinoamericano durante la última década. Sin embargo, parecería que poco o nada queda de ellos después de la "marea rosada"... A estas alturas, sería ingenuo poner en duda que otra etapa del regionalismo latinoamericano haya entrado en su recta final. ${ }^{19}$

Es cierto que la mayoría de los líderes de los gobiernos progresistas latinoamericanos, tal vez preocupados particularmente por el MERCOSUR, llegaron a advertir en el discurso cuán crucial era este punto. En ese sentido, muchos de esos gobiernos postularon una vocación de mayor profundidad integracionista, representada en el campo ideal en procesos de la naturaleza del MERcosur o del ALBA, basados en una llamada "apuesta posliberal", con compromisos de avance en políticas más integrales, orientadas a superar un ciclo de excesiva priorización comercialista. De allí que autores como José Antonio Sanahuja, Pía Riggirozzi y Diana Tussie hayan fundado el registro de ese nuevo "regionalismo posliberal" en asociación directa con la acción de los gobiernos progresistas de la "década social" (2004-2014). Pero tal vez el problema radique fundamentalmente en la heurística utilizada para fundamentar los juicios: una cosa han sido las declaraciones y aun las resoluciones tomadas en las Cumbres y otra muy distinta la conducción efectiva y la administración cotidiana del bloque.

En efecto, esa vocación de profundizar los objetivos de la integración regional en el MERCOSUR quedó plasmada, por ejemplo, en documentos como el Consenso de Buenos Aires (octubre de 2003) o el Acta de Copacabana (noviembre de

19 "El regionalismo latinoamericano, más allá de los «pos». El fin del ciclo y los fantasmas globales", Nueva Sociedad, 2018, núm. 275, pp. 106 y 119 . 
2004), impulsados por quienes entonces eran presidentes de Brasil y Argentina, es decir Luiz Inácio Lula da Silva y Néstor Kirchner, respectivamente. También fue ejemplo de esa tendencia la negativa de todos los Estados parte del bloque junto con Venezuela a sumarse al proyecto del Área de Libre Comercio de las Américas (ALCA), en ocasión de la IV Cumbre de las Américas de Mar del Plata en noviembre de $2005 .{ }^{20}$ Estos pronunciamientos reflejaron en su momento las potencialidades de un nuevo acuerdo político que se proyectaría sobre el MERCOSUR, pero con una posterior vocación continental, desde los nuevos mecanismos entonces emergentes como la antes mencionada ALBA, la UNASUR o la CELAC. ${ }^{21}$ Las definiciones parecían orientarse entonces a la conformación de espacios integrados de desarrollo como soporte de una inserción internacional más autónoma de la región. En los mismos textos propositivos se hacía hincapié en que estos nuevos formatos de integracionismo y de inserción internacional resultaban bases decisivas para sustentar el cambio social con una forma de crecimiento económico más autónoma, menos dependiente de los commodities, con mayor articulación entre complementación productiva, "comercio justo" y desarrollo con equidad. ${ }^{22}$

Sin embargo, la persistencia de dificultades en la agenda comercial, los problemas para avanzar en proyectos comunes en materia de complementación productiva y en infraestructura, la persistencia de conflictos originados en la divergencia de los proyectos construidos desde el espacio de los Estados nacionales de espaldas a la región, la no superación de las asimetrías de los socios, el incumplimiento frecuente de lo

${ }^{20}$ E. Pantojas García, "El alca: un inventario de su proceso", Anuario de la Integración Regional de América Latina y el Gran Caribe, 2007, núm. 6, coord. por A. Serbin, P. Isa-Contreras y L. Peña, pp. 37-45.

${ }^{21}$ Cf. www.alba-tcp.org; www.unasursg.org; www.sela.org/celac.

${ }^{22} \mathrm{El}$ autor ha trabajado especialmente esas definiciones en algunos de sus trabajos. Cf. Mercosur 20 años, Montevideo, CEFIR, 2011, y "El futuro de la integración regional: entre la administración de conflictos y la necesidad de pensamiento estratégico" en MERCosur. Prospectiva 20 años, Montevideo, CEFIR-FESUR, 2012, pp. 19-28. 
acordado, la emergencia de contenciosos bilaterales, la falta de concertación de posturas en organismos multilaterales o plurilaterales, ${ }^{23}$ así como los casi nulos avances en materia de agenda externa común, terminaron por restar credibilidad al nuevo enfoque de integración y regionalismo "posliberal", precisamente en un momento de grandes desafíos externos y de reconfiguración geopolítica.

Este fracaso, si bien ha terminado de consolidarse con el giro político más actual en el Continente, ya estaba perfilándose desde hacía varios años, cuando todavía imperaban los gobiernos progresistas. En enero de 2014, antes del cambio político en Brasil y Argentina, el entonces presidente uruguayo José Mujica advertía en un reportaje que el MERcosur debía

ajustar lo jurídico en lo posible a lo que somos y no a lo que soñamos que deberíamos ser, creo que esto merece una discusión... El MERcosur tiene un problema interno y tiene que revisar, revisarse a sí mismo, qué es lo que sigue vigente y lo que no sigue vigente... Sería mejor que nos sinceremos y si esos mecanismos no sirven tratemos de construir otros que sean flexibles, que respondan más a la época actual. Lo que no podemos seguir es en una especie de mentira institucional: tenemos una letra, pero vamos por otro camino. ${ }^{24}$

Más de dos años después, ya convertido en un octogenario senador, Mujica insistía ${ }^{25}$ en que, si bien seguía apostando

${ }^{23}$ Un ejemplo ilustrativo de ello ha sido la participación de Argentina, Brasil y México en el G20 financiero. No sólo no intentaron investir la representación oficiosa de América Latina en ese foro, sino que tampoco llegaron a concertar sus posiciones entre sí.

${ }^{24}$ Cf. "Arremete Mujica contra países del Mercosur", El Observador (con información de AFP), 11 de enero de 2014, en www.elobservadordigital.com.

${ }^{25}$ En la clase inaugural del curso internacional América Latina: ciudadanía, derechos e igualdad, coorganizado por clacso, la UMET y FLACso Brasil, Buenos Aires, 17 de marzo de 2016. 
por el MERCOSUR y la integración como caminos insoslayables para el desarrollo regional, "ya no es tiempo de decir simplemente que no. Hay que marcar un rumbo propositivo".

Hay que inscribir este debate sobre el fracaso del "regionalismo posliberal” en un marco geopolítico continental. El escenario de las últimas décadas en los procesos integracionistas y regionalistas en América Latina se dibuja a trazo grueso, identificando, por lo que toca a la integración subregional, dos dinámicas divergentes en el Continente. Mientras que los países con costas en el Pacífico han ido consolidando su esquema de integración enmarcado en una trayectoria de fuerte apertura a la economía global, a partir de la Alianza del Pacífico y bajo el liderazgo norteamericano que hoy parece replegarse, los países asociados en torno al MERCOSUR y el ALBA procuraron en el último decenio (con dificultades importantes y con giros significativos de orientación en los últimos años) consolidar la integración regional como un mecanismo que favoreciera una inserción más autónoma en el escenario global. Como vimos, más allá de logros parciales, los fracasos debilitaron esta segunda vía progresista.

En el caso del Mercosur, el factor fundamental fue la falta de voluntad política de los dos grandes del bloque, Argentina y especialmente Brasil. En el caso del ALBA, el gran motivo del declive fue la implosión del liderazgo venezolano tras la caída de los precios internacionales del petróleo. En ese marco, la vía del aperturismo comercialista y de la aceptación de las nuevas reglas de negociación en bienes, servicios e inversiones, pese a todos sus efectos en las políticas internas de los Estados nacionales, parece proyectarse como pauta dominante en casi todo el Continente. No resulta casual que muchas de las medidas más significativas del "programa contrarreformista" de los nuevos gobiernos de derecha o centro derecha en el Continente (reformas laborales, previsionales, congelamiento de la inversión pública y del gasto social, reformulación de las políticas de inserción, etcétera) se presen- 
ten como consecuencias "naturales" de un ajuste indispensable al "Nuevo Mundo". 26

Mientras se confirma el giro netamente "comercialista" de un proceso de integración ambicioso como el MERCOSUR, ${ }^{27}$ ante las diferencias políticas entre los Estados (acrecentadas por la crisis venezolana) se ha configurado un inédito Grupo de Lima, ${ }^{28}$ que avanza en decisiones que involucran a la región desde la absoluta transgresión de los circuitos institucionalizados de carácter regional. En un mismo sentido, bajo el liderazgo de Brasil, se "dinamitó” la UNASUR, definida en forma sarcástica por Benzi y Narea, en su artículo citado, como "un viejo anhelo de los estrategas geopolíticos brasileños, desempolvado por esa banda de ilusionados del Partido de los Trabajadores”. Esto ocurrió en abril de 2018, con el anuncio conjunto del "retiro temporal" de seis Estados parte, ${ }^{29}$ los mercosureños Brasil, Argentina y Paraguay (con la resistencia de Uruguay) y los tres socios sudamericanos de la Alianza del Pacífico (Colombia, Perú y Chile).

En la actualidad, no es que hayan desaparecido de las filas del progresismo latinoamericano las visiones críticas, por

${ }^{26}$ Poco antes de que un tribunal de Porto Alegre ratificara la condena del juez Moro sobre Lula, el actual Presidente brasileño Temer, en su discurso pronunciado en el Foro Económico Global Mundial de Davos, realizó una contundente defensa de las reformas liberales emprendidas por su gobierno, al tiempo que observaba el "nuevo" Brasil como "un Brasil de responsabilidad, no de populismo", y abogó por la "apertura" y en contra del "aislacionismo".

${ }^{27}$ En la Cumbre de Presidentes del mercosur reunida en Mendoza los días 20 y 21 de julio de 2017, el Presidente brasileño Temer, luego de asumir la Presidencia pro tempore del bloque, se comprometió a continuar y profundizar el "giro comercialista" del Mercosur: "La cumbre de Mendoza será recordada como el marco del esfuerzo del rescate de la vocación original de nuestro bloque".

${ }^{28}$ El llamado "Grupo de Lima" es una instancia multilateral informal que se estableció tras la denominada Declaración de Lima del 8 de agosto de 2017, a propósito de la crisis política venezolana. A partir de ello se ha seguido reuniendo con el aval manifiesto de los EE. UU., la UE y la OEA.

${ }^{29}$ Cabe apuntar que UNASUR mantiene su secretaría general acéfala desde enero de 2017, fecha en la que terminó su mandato Ernesto Samper. 
ejemplo, de los fuertes condicionamientos de los Tratados de Libre Comercio clásicos, en especial en asuntos estratégicos como compras gubernamentales, propiedad intelectual, tratamiento igualitario de empresas nacionales y extranjeras, dilucidación de contenciosos en el CIADI (organismo anexo al Banco Mundial) y no en tribunales competentes acordados por los países firmantes, entre otros aspectos. Aunque los marcos de negociación han cambiado y con China, en particular, parecen abrirse condiciones de mayor flexibilidad, las posturas críticas a este tipo de acuerdos persisten y mantienen fundamento. Sin embargo, el statu quo de algunos integracionismos paralizados, sumado a los retos de un contexto acuciante de desaceleración económica, de cambios tecnoeconómicos y de reformulación de las negociaciones en comercio de bienes, inversiones y servicios, ya suscita descontentos expandidos. Las posturas de quienes en el Continente exigen pautas de inserción internacional capaces de afirmar la conformación de cadenas de valor regionales, con desarrollos industriales compartidos y mayor agregación de valor, han comenzado a enfrentar cierto desaliento frente a la intocada dependencia de la exportación de commodities que exhibían (y continúan exhibiendo) los países de la región, sus dificultades para enfrentar la desaceleración económica y su marginación relativa de los principales circuitos comerciales en el mundo.

Desde una perspectiva crítica y a la vez equilibrada, el chileno Alberto van Klaveren tampoco ha ahorrado críticas a su balance sobre el regionalismo sudamericano reciente: "La integración económica ha tenido una evolución compleja y muy poco ortodoxa. La remoción de barreras comerciales ha sido parcial e incompleta. Las uniones aduaneras no suelen ser lo que parecen... La retórica ha superado los hechos". Sin embargo, desde una perspectiva que claramente se alinea con el enfoque que ha predominado en Chile durante todos los últimos gobiernos pospinochetistas, van Klaveren reafirma la persistencia de "un potencial de convergencia de procesos de integración en América Latina”, poniendo como 
ejemplo la "convergencia en la diversidad" entre la AP y el MERCOSUR, impulsada como propuesta por el gobierno de Chile en el 2014. ${ }^{30}$

Según puede observarse, aunque todavía persista el debate en la academia, las tendencias predominantes que surgen de las circunstancias económicas globales y de los procesos integracionistas prevalecientes en América Latina, también desde los balances de lo efectivamente concretado en las propuestas de "regionalismo" impulsadas en los hechos por los gobiernos progresistas, parecen fundamentar que los derroteros más recientes del MERcosur se inscriben en un cambio de modelo mucho más orientado a un énfasis "liberal-comercialista" y a una profundización de la pauta de "regionalismo abierto", coincidente con el orden económico global.

Nos interesa ahora responder a la segunda pregunta de investigación formulada al comienzo del artículo. ¿Cuánto influyó en este cambio de paradigma integracionista en el MERCosur el dramático giro político vivido en Brasil en los últimos años?

LAS CONSECUENCIAS DEL FACTOR BRASIL EN EL FUTURO DEL MERCOSUR

Para analizar las dimensiones del giro político de Brasil y, en particular, las dimensiones del viraje de su política exterior, resulta prudente, antes que nada, evitar análisis coyunturalistas e inscribir el estudio en perspectivas y discusiones de más largo aliento. Refiramos desde el inicio algunas pistas para enmarcar el análisis de la coyuntura, a fin de elaborar un argumento más consistente. En primer lugar, varios autores han comenzado a reconocer la política exterior brasileña del

30 "El eterno retorno del regionalismo latinoamericano", Nueva Sociedad, 2018, núm. 275, pp. 70-71. También, sobre este punto, puede consultarse La Alianza del Pacifico y el Mercosur. Hacia la convergencia en la diversidad, Santiago de Chile, Naciones Unidas-CEPAL, 2014. 
siglo XXI como una política posdiplomática, en la que Itamaraty ha perdido centralidad y han ganado peso los actores partidarios y los grupos de interés, consecuencia tanto de la complejización de la agenda, como de la "democratización" del régimen de elaboración de esta política. ${ }^{31}$ Asimismo, la cuestión de la efectividad del liderazgo brasileño en la región resulta también un punto especialmente debatido en los últimos tiempos en el medio académico. Las interpretaciones sobre el protagonismo internacional y el liderazgo regional brasileño van desde quienes afirman su concreción ${ }^{32}$ hasta quienes la cuestionan, ${ }^{33}$ basándose en diferentes argumentos. Asimismo, otros autores, como Amâncio de Oliveira y Janina Onuki, apuntan que el análisis de las diferencias en la orientación de la política exterior, como variable dependiente, debe concentrarse en si el relacionamiento privilegia relaciones Norte-Sur o Sur-Sur, así como en la actitud de los

${ }^{31}$ D. Belém Lopes y C. López Burian, "De Rousseff a Temer, o de cómo la política doméstica condiciona la política exterior", en A. Busso (comp.), La inserción internacional argentina en una doble transición, Rosario, Universidad Nacional de Rosario-UNR Editora, 2018.

32 M. G. Saraiva, "Brazilian Foreign Policy towards South America during the Lula Administration: Caught between South America and Mercosur", Revista Brasileira de Política Internacional, 53 (2010), núm. esp., pp. 151-168; L. Pinheiro y G. Gaio, "Cooperation for Development, Brazilian Regional Leadership and Global Protagonism", Brazilian Political Science Review, 8 (2014), núm. 2, pp. 8-30.

${ }^{33}$ Entre otros, véase S. Burges, "Revisiting Consensual Hegemony: Brazilian Regional Leadership in Question", International Politics, 52 (2015), pp. 193-207; D. Flemes, "Brazilian Foreign Policy in the Changing World Order", South African Journal of International Affairs, 16 (2009), núm. 2, pp. 161-182; D. Flemes y T. WojCZEwski, "Contested Leadership in International Relations: Power Politics in South America, South Asia and Sub-Saharan Africa" (GIGA Working paper, 121), sSRN, 4 de febrero de 2010, en https:/ /ssrn.com/abstract=1547773; D. Flemes y L. WeHner, "Drivers of Strategic Contestation: The Case of South America", International Politics, 52 (2015), pp. 163-177; A. Malamud, "A Leader without Followers? The Growing Divergence between the Regional and Global Performance of Brazilian Foreign Policy", Latin American Politics and Society, 53 (2011), núm. 3, pp. 1-24. 
actores locales frente a la integración regional. ${ }^{34}$ Este último tipo de acercamiento pone de relieve cómo la política doméstica influye cada vez más en la política exterior brasileña. La necesidad de mantener los votos en un parlamento particularmente fragmentado hace que estrategias multilaterales y políticas de larga data se abandonen por un enfoque más comercialista y clientelar, que apunta a intereses particulares de los cabilderos que sustentan en términos económicos y electorales a buena parte de la coalición de apoyo de Temer. ${ }^{35}$ Por su parte, también hay académicos que priorizan la influencia de otro tipo de variables, como el impacto del desafío de China y su influencia en la región. ${ }^{36}$

Estos debates no sólo se han dado en el ámbito académico y político partidario. Desde el ámbito generalmente opaco y cuidadoso de Itamaraty, dos auténticos caudillos de la política exterior y de la diplomacia brasileña en las últimas décadas, como Celso Lafer y Celso Amorim, han debatido

34 "Eleições, Partidos Políticos e Política Externa no Brasil", Revista Política Hoje, 19 (2010), num. 1, pp. 144-185.

${ }^{35}$ D. Belém Lopes y C. López Burian, "La política exterior brasileña del siglo xxı: un cambio epocal", en D. Abente Brun y C. Gómez Florentín (eds.), Panorama de las Relaciones Internacionales en el Paraguay actual, Asunción del Paraguay, Conacyt-Prociencia-Universidad Nacional de Asunción, 2018, pp. 99-129.

${ }^{36}$ J. Dosch y D. Goodman, "China and Latin America: Complementarity, Competition, and Globalisation", Journal of Current Chinese Affairs, 41 (2012), núm. 1, pp. 3-19; R. Jenkins, "China and Brazil: Economic Impacts of a Growing Relationship", Journal of Current Chinese Affairs, 41 (2012), núm. 1, pp. 21-47; R. Jenkins, "Chinese Competition and Brazilian Exports of Manufactures", Oxford Development Studies, 42 (2014), pp. 395-418; G. STRÜVER, “«Bereft of Friends»? China's Rise and Search for Political Partners in South America", Chinese Journal of International Politics, 7 (2014), pp. 117-151; F. Urdinez, "The Political Economy of the Chinese Market Economy Status Given by Argentina and Brazil", CS, 2014, núm. 14, pp. 47-75; F. Urdinez et al., "MERCosur and the Brazilian Leadership Challenge in the Era of Chinese Growth: A Uruguayan Foreign Policy Perspective", New Global Studies, 10 (2016), pp. 1-25. 
públicamente entre sí. ${ }^{37}$ Aquél ha acusado a Lula de "falta de realismo" con su política exterior de gran "actor global", mientras que éste ha replicado a Lafer con la acusación de portar una tendencia "nanomaníaca". Si bien los analistas tienden a advertir que la política exterior brasileña "perdió prioridad" durante los dos gobiernos de Dilma Roussef, coinciden en señalar que el gran cambio se dio a partir de la asunción presidencial de Temer. ${ }^{38}$

Sin embargo, más allá del discurso integracionista, las perspectivas reales de un MERCOSUR con doble membresía, "geometría variable" y "dos velocidades", con mayor flexibilidad comercial, profundización en variables políticas y ampliación con menores exigencias para los nuevos socios, pareció prefigurarse, en efecto, como una tendencia posible durante el segundo mandato inconcluso de Dilma Rousseff. A pesar de que los voceros brasileños de Itamaraty reiteraban la necesidad de que en el MERCOSUR se debía negociar como bloque y que mantenían sus críticas y recelos frente a la Alianza del Pacífico (a la que se continuaba observando como "un contrapeso regional al MERcosur"), en el último año del segundo gobierno de Dilma y en particular luego del cambio de gobierno en Argentina, con la asunción presidencial de Mauricio Macri, las autoridades brasileñas, al menos en sus pronunciamientos públicos, se esforzaron por explicitar una postura favorable a todo avance posible en la perspectiva de un acuerdo comercial con la Unión Europea, postura que respaldaban tanto el nuevo gobierno argentino, como -y con especial entusiasmo- Uruguay y Paraguay. ${ }^{39}$

Fue en las circunstancias de finales del 2015 y del primer trimestre de 2016, con una arremetida desestabilizadora en

${ }^{37} \mathrm{El}$ primero fue canciller durante los gobiernos de Fernando Collor (1992) y de Fernando Henrique Cardoso (2001-2002), mientras que el segundo, durante los dos gobiernos de Lula (2003-2010), a más de Ministro de Defensa de Dilma Roussef (2011-2015).

38 Cf. Belém Lopes y López Burian, art. cit.

39 Cf. R. Bernal-Meza y L. Bizzozero, La política internacional de Brasil: de la región al mundo, Montevideo, Ediciones Cruz del Sur, 2014. 
contra del gobierno de Dilma Rousseff (facilitada por los escándalos de corrupción que alcanzaban en forma directa al Partido de los Trabajadores y cruzaban prácticamente todo el espectro político brasileño), cuando comenzó a concretarse el territorio abonado para un cambio más radical en la política exterior brasileña, enmarcada, claro está, en la perspectiva de un nuevo gobierno completamente diferente, impulsado tras el alejamiento de Dilma mediante el instrumento del $\mathrm{im}$ peachment. Tal vez como síntesis de todo este clima de radicalización aperturista puedan recogerse las siguientes palabras de Rubens Barbosa, Presidente del Consejo de Comercio Exterior de la Federação das Indústrias do Estado de São Paulo (FIESP) y todo un referente del empresariado paulista, pronunciadas en enero de 2016:

En caso de que los acuerdos EE. UU.-Unión Europea y de EE. UU. con países asiáticos sean concluidos, el MERCosUR quedará alejado de los dos mayores flujos de comercio internacional. La eliminación de tarifas entre los países miembros de esos dos bloques afectará aún más la competitividad de los productos brasileños, que prácticamente quedarán excluidos de esos mercados. La Alianza del Pacífico (Chile, México, Perú y Colombia) representó una acción geoeconómica importante por la aproximación de los EE. UU. y de Asia. El MERcosur, que pidió ser observador de la Alianza, se encuentra en una situación de casi total aislamiento. En los últimos diez años, el bloque firmó apenas tres acuerdos de libre comercio, con Israel, Egipto y con la Autoridad Palestina, además de acuerdos de preferencia arancelaria con India y Sudáfrica. La negociación del grupo con la Unión Europea pasa a ser crucial para poder estar en sintonía con esas transformaciones globales. ${ }^{40}$

${ }^{40}$ Cf. R. Barbosa, "Revolución comercial", El País, 13 de julio de 2014, en http://www.elpais.com.uy/opinion/revolucion-comercial.html. Las expresiones de Barbosa resaltaban su significación pues también representaban un cambio de posición de la FIESP, a la que Dilma venía otorgando beneficios para proteger sus industrias de los efectos de contrarrestar los embates de sus otros enemigos en el sector empresarial y 
Con la separación inicial de Dilma de la presidencia efectivizada en mayo, la asunción del gobierno provisorio de Michel Temer y, en particular, con la designación de José Serra como nuevo canciller, todo quedó muy bien servido para una aceleración profunda en los cambios de la política exterior. Por muchas razones, José Serra era el hombre indicado para esa tarea. De vieja y conocida militancia contraria al MERCOSUR, con 74 años por entonces, Serra había sido gobernador de San Pablo y senador por el PSDB, candidato presidencial por este partido derrotado en 2002 por Luiz Inácio Lula da Silva y en 2010 por Dilma Rousseff. Para muchos analistas, en esos momentos todavía mantenía ambiciones presidenciales, por lo que podría aprovechar un fuerte protagonismo en la cancillería para perfilarse como candidato para las elecciones de 2018.

Sus primeros pronunciamientos al asumir el cargo no sólo resultaron especialmente radicales, sino que fueron registrados como una "Guinada à direita no Itamaraty": su alocución inaugural fue recibida con una ovación por parte del cuerpo diplomático presente, otra señal del compromiso de distintos sectores de la administración pública brasileña en la jugada contra el gobierno del PT. En un artículo especialmente publicado para el influyente diario argentino $\mathrm{La} \mathrm{Na}$ ción, el periodista Emilio Cárdenas hizo un resumen de su discurso de asunción bajo el sugestivo título de "El nuevo decálogo de la política exterior de Brasil". Entre los "diez mandamientos", destacó los siguientes:

El primero se refiere a la sustancia de la diplomacia brasileña... "Primero Brasil"... El segundo mandamiento es también muy fuerte. Brasil estará atento (no pasivo) en la defensa de la democracia... El tercero, a su vez, tiene que ver con el anuncio de que Brasil asumirá un rol activo en la defensa del medio ambiente... El cuarto se refiere a la actuación futura de

político. Cabe señalar que la FIESP fue actor diligente en lo que atañe a la destitución de Rousseff. 
Brasil en los foros internacionales... [con] una mención expresa a la prioridad que Brasil asigna a todo lo financiero y a lo comercial... El quinto postulado enunciado por Serra se relaciona con la participación de Brasil en el comercio internacional..., sin atarse a un único esfuerzo multilateral (el de la omc) que está visiblemente empantanado y sí... abrir cada puerta comercial bilateral que existe... La sexta directiva tiene que ver con la urgencia de negociar los temas comerciales siempre desde la fortaleza que a Brasil le confiere el poder contar con un atractivo mercado doméstico... La séptima definición de política exterior se refiera a la Argentina... Por ello nos propone una aventura, la de renovar -juntos- el MERcosur... Esto supone devolverle su esencia original: la de naturaleza comercial. Pero con un agregado significativo: el de construir también puentes con la Alianza del Pacífico... La octava directiva pertenece también al capítulo comercial... proponiendo ampliar y profundizar las relaciones con socios no tradicionales, como la Unión Europea, los Estados Unidos y Japón. Abrirse, en lugar de encerrarse. A lo que se suma enseguida la novena directriz, que tiene que ver con la necesidad complementaria de incrementar las relaciones comerciales y financieras con Asia, incluyendo naturalmente a sus dos gigantes: China y la India, muy especialmente... El último capítulo de su enumeración precisa de directivas... hace a la necesidad de mejorar la productividad y la competitividad de nuestras economías. ${ }^{41}$

Me extendía en la cita, porque el primer canciller del gobierno de Temer utilizó su discurso de asunción para sintetizar la nueva política exterior de Brasil para el futuro próximo. Las nuevas directrices anunciadas por Serra configuraban una escisión radical con respecto de las políticas petistas de los últimos años, más allá de lo antes anotado

41 "El nuevo decálogo de la política exterior de Brasil”, La Nación, 26 de mayo de 2016, en https://www.lanacion.com.ar/1902513-el-nuevodecalogo-de-la-politica-exterior-de-brasil. 
acerca del realismo gradualista de la política exterior de Roussef, en especial en su segundo mandato. Implicaban a su vez un nuevo marco insoslayable para la consolidación de otro rumbo para el MERcosur en su conjunto. Tras el giro a la derecha de los cambios de gobierno en Argentina (2015) y en Paraguay (2013, con la llegada de Horacio Cartes del Partido Colorado a la Presidencia), además del cambio más gradualista en las posturas uruguayas (con Tabaré Vázquez nuevamente en la presidencia desde 2015) y el desplome venezolano (especialmente a partir de la asunción presidencial de Nicolás Maduro, luego de la muerte de Hugo Chávez, en 2013), el cambio que anunciaba Serra llegaba en el momento justo y no tendría mayores oposiciones de parte de las autoridades de los otros Estados que informan el bloque.

Como era previsible, los anuncios de Serra fueron duramente criticados por las autoridades del gobierno depuesto, en particular por parte de los principales responsables de establecer los cimientos de la política exterior petista, en especial durante los gobiernos de Lula, el otrora canciller Celso Amorim ${ }^{42}$ y su segundo y luego Alto Representante del mercosur, Samuel Pinheyro Guimaraes, quien, por ejemplo, señaló en mayo de 2016:

La celebración de acuerdos de libre comercio sería el fin del Mercosur. Si esto es así, el acuerdo mercosur-Unión Europea funcionaría, en realidad, como el primero de una serie de acuerdos de libre comercio con los Estados Unidos, China y Japón. Los países del mercosur, en especial Brasil y la Argentina terminarían abriendo totalmente sus mercados para los productos industriales europeos y luego para los norteamericanos, chinos y japoneses; darían concesiones asimétricas, por ejemplo, en compras gubernamentales y a cambio recibirían concesiones irrisorias en materia agrícola. Incluso las mayores concesiones serían irrisorias si a cambio se pierden las posibi-

42 Cf. P. Mascarenhas, "Celso Amorim: Brasil precisa de novo rumo para reconquistar credibilidade", Jornal do Brasil, 19 de junio de 2016. 
lidades de industrialización. Los acuerdos de libre comercio tan defendidos por los grandes medios, académicos e importadores, significarían el fin del MERCOSUR como instrumento de industrialización y desarrollo. ${ }^{43}$

Los periodistas y analistas de perfil progresista no fueron menos críticos. En una visión de síntesis sobre los anuncios de Serra, Eric Nepomuceno advirtió en la misma época que

el Mercosur es otro blanco de la mirada furibunda de Serra... Más que nunca, el comercio será el foco principal de la política externa, pero ya no en el proyecto Sur-Sur de Lula da Silva: Washington vuelve a ser la capital. Con eso, las negociaciones bilaterales volverán a imperar y las multilaterales pasan a las sombras. ${ }^{44}$

Por su parte, el reconocido historiador Luis Alberto Moniz Bandeira, recientemente fallecido, opinó también sobre este giro radical de la política exterior brasileña, aunque desde una perspectiva más global:

El Brasil está en medio de una guerra geoeconómica, una segunda Guerra Fría, peleada por diferentes medios, en la cual los Estados Unidos tratan de preservar a cualquier costo su hegemonía... El Brasil es el mayor socio comercial de China y, como cierta vez dijo el expresidente Richard Nixon, para donde vaya Brasil irá toda la América Latina. Por eso era preciso mudar su dirección. ${ }^{45}$

${ }^{43}$ Cf. M. Granovsky, "Entrevista a Samuel Pinheiro Guimaraes, ex vicecanciller de Lula. «En Brasil hubo una conspiración»", Página 12, 29 de mayo de 2016.

44 "Brasil y el vuelco radical en su política externa", La Jornada, 22 de mayo de 2016, en http://www.jornada.com.mx/2016/05/22/opinion/01 $6 \mathrm{a} 2$ pol.

${ }^{45}$ Cf. S. LiRio, "Brasil: el golpe y la geopolítica. Entrevista al Profesor Luis Alberto Moniz Bandeira”, AmerSur, 19 de mayo de 2016, en www. amersur.org/tag/luiz-alberto-moniz-bandeira/. 
Ya desde su período como Presidente interino, en el marco de un plan de reformas que anunció con el título de Un Puente para el Futuro, Temer había anunciado una "nueva política exterior", intentando trasmitir una idea de "refundación”. Sus líneas estratégicas fueron las anunciadas por Serra. Y ellas requerían de un amplio paquete de reformas domésticas en concordancia: desregulación laboral, ajuste en el sistema previsional, repliegue del Estado y de sus inversiones, mayor protagonismo de los empresarios en áreas decisivas de gobierno. Sin embargo, al extremismo de las posturas de Serra y las sospechas de que portaba aspiraciones presidenciales se sumaron acusaciones de corrupción, lo que provocó su renuncia efectivizada en marzo de 2017. Lo sucedió como canciller Aloysio Nunes Ferreira, otrora ministro de los gobiernos de Fernando Henrique Cardoso e integrante como legislador de la Comisión de Relaciones Exteriores y Defensa Nacional (CREDEN) de la Cámara de Representantes. Aunque con un estilo menos personalista y altisonante, Nunes continuó con los lineamientos inaugurados por Serra. En esa misma dirección y como reflejo de toda una nueva inserción del sector privado en la conducción del Estado, habilitó el protagonismo y las demandas de corporaciones especialmente poderosas, en particular aquellas más representativas de los sectores financieros y de los agronegocios. ${ }^{46}$

Este último factor resultó indispensable para entender la dinámica política del gobierno de Temer. Su asignación de ministerios a los partidos y sectores de su base aliada otorga un enorme poder a ciertas corporaciones que lo apoyan, aunque siempre con condiciones. El "Centrão" (como se denominó al núcleo de sus apoyos en el Congreso) agrupa a cuatro de las bancadas suprapartidarias más importantes del Congreso, todas ellas con agendas conservadoras. La evangélica, la de los grandes empresarios, la que impulsa políticas de seguridad y la de la tenencia de armas y la ruralista. La primera, que defiende los valores de la "familia tradicional

${ }^{46}$ Cf. Belém Lopes y López Burian, art. cit. 
brasileña”, se opone al aborto y al matrimonio igualitario, entre otros asuntos. La segunda impulsó el proyecto de reforma laboral y la tercera propone una agenda de seguridad pública de "mano dura". Los ruralistas, el Frente Parlamentario de la Agricultura (FPA), son una pieza de mucha importancia tanto de soporte como de aporte a los votos necesarios en el Congreso. Representa los intereses del sector de agronegocios e incluye a más de 200 diputados. ${ }^{47}$

La plataforma de reivindicaciones ruralistas fue muy atendida por el gobierno brasileño, presionando con sus demandas también las orientaciones de la política exterior. Este factor, que suele no registrarse suficientemente en su centralidad, ejemplifica de manera muy clara el peso renovado de este tipo de corporaciones en la trayectoria de las políticas del gobierno de Temer. Por lo demás, esta otra dimensión de las decisiones en la política exterior brasileña, con una renovada centralidad como "ganadores" de la coyuntura brasileña de los sectores financieros y de agronegocios, a lo que se suma un acompañamiento cauto y menos protagónico de la otrora todopoderosa Federación de Industrias del Estado de San Pablo (FIESP), contribuye también al giro "liberal-comercial" del MERCOSUR en su conjunto.

\section{Algunos posibles escenarios}

DE CORTO Y MEDIANO PLAZO

Las dos preguntas de investigación que se anunciaban en la introducción de este artículo parecen confirmar las hipótesis que configuran el núcleo argumental presentado: el MERCOSUR como bloque regional parece confirmar un cambio de modelo de integración y los acontecimientos del último tiempo en Brasil han sido un factor que ha impactado con fuerza en la misma dirección. ¿Cuál parece ser la reacción del MERCosur ante la envergadura de estos procesos? 
Ya sin la presencia formal de Venezuela, en el 2017 el MERCOSUR pareció profundizar su reorientación de rumbos en una perspectiva de mucha mayor centralidad a los objetivos comerciales. Con un papel activo del gobierno argentino de Mauricio Macri durante el primer semestre, en el que ejerció pro tempore la Presidencia del bloque, los movimientos de avance en la negociación del acuerdo comercial con la Unión Europea y las señales de acercamiento del bloque hacia la Alianza del Pacífico se han venido multiplicando. Los matices sobre qué hacer con respecto del agravamiento de la crisis política venezolana (provenientes de Uruguay) no han dificultado la confirmación del giro comercialista con foco en los dos movimientos arriba señalados.

En la Cumbre de Presidentes del mercosur celebrada en Mendoza los días 20 y 21 de julio del 2017, ${ }^{48}$ estas coincidencias de fondo se profundizaron de manera ostensible. Más allá de las controversias sobre la declaración no poco light del bloque sobre la situación venezolana, una visión más profunda de los discursos y las resoluciones permite advertir la consolidación de lo que algunos analistas han comenzado a denominar Giro refundacional del MERCosur hacia enfoques prioritariamente comercialistas. Como prueba de ello, el presidente uruguayo Tabaré Vázquez propuso seis pautas de acción para el bloque, que incluyeron "avanzar en la labor del grupo de fortalecimiento económico-comercial”, "pronta concreción del acuerdo con la Unión Europea”, "jerarquizar y sistematizar las relaciones con la República Popular China" y "acordar mecanismos que permitan a los Estados parte del MERCOSUR interactuar con la Alianza del Pacífico". ${ }^{4}$ El presidente brasileño Temer, luego de asumir pro tempore la

48 Esta XLV Cumbre de Presidentes del Mercosur se formalizaba poco menos de dos años después de la última, celebrada en Asunción del Paraguay en diciembre de 2015.

${ }^{49}$ Cf. "Vázquez propuso en Mendoza seis medidas para revitalizar el Mercosur", 21 de julio de 2017, en https://www.presidencia.gub.uy/sala-de-medios/audios/audios-breves/vazquez-medidas-revitalizar-mercosur-cumbre-mendoza. 
Presidencia del bloque, declaró: "el progreso que hemos obtenido en la presidencia argentina", comprometiéndose a continuar y profundizar lo que no dudó en calificar de "giro comercialista" del mercosur. "La cumbre de Mendoza será recordada como el marco del esfuerzo del rescate de la vocación original de nuestro bloque". ${ }^{50}$

Desde el 2016, Uruguay viene liderando -un tanto simbólicamente- la necesidad de abrir negociaciones directas con China a favor de la concreción de un TLC, tanto desde el MERCOSUR como en solitario. Esta última posibilidad, un tanto descabellada a partir de las asimetrías en juego, ha sido en principio desechada por China y vista con clara desconfianza por Argentina y Brasil, que han sostenido públicamente la necesidad de encarar una negociación de este calado desde el bloque y no desde uno de los Estados parte. Sin embargo, a la hora de las concreciones, el MERcosur, una vez más, no ha demostrado demasiada eficacia, al afrontar, cuando menos por ahora, este reto en conjunto. Si bien el gobierno y, en particular, la cancillería uruguaya no han desistido de impulsar la iniciativa, aunque sea en solitario, las dificultades para concretar esa vía parecen inmensas. Más allá de las consecuencias que ello ocasionaría en la situación de Uruguay en el MERCOSUR y de las dificultades técnicas y productivas de un acuerdo de esa magnitud y con escalas tan asimétricas, el gobierno uruguayo del Frente Amplio no parece tener las condiciones políticas necesarias para afrontar un desafío de esa envergadura. ${ }^{51}$ Asimismo, tampoco parecen haberse cali-

${ }^{50}$ Pablo S. Fernández, "Los presidentes del mercosur se comprometen a revitalizarlo", El País, 22 de julio de 2017, en https://plus.google. $\mathrm{com} /$ share? url=http://www.elpais.com.uy/informacion/presidentesmercosur-se-comprometen-revitalizarlo.html.

${ }^{51}$ Los planteamientos al respecto del canciller uruguayo Rodolfo Nin Novoa han despertado críticas desde algunos sectores del Frente Amplio. Incluso, ese controvertido escenario se ha reiterado en los órganos de conducción del partido oficialista a la hora de aprobar el Tratado de Libre Comercio, ya firmado por los gobiernos de Chile y Uruguay, que finalmente se aprobó en junio de 2018. 
brado concienzudamente las graves consecuencias económicas y de toda índole de un acuerdo de esa naturaleza. ${ }^{52}$ En cualquier hipótesis, parece evidente que las prioridades del MERCosur, en cuanto bloque, se han terminado de afincar en esos dos objetivos más específicos de la finalización de la negociación del acuerdo comercial con la Unión Europea y de la convergencia con la Alianza del Pacífico.

Ha sido el atribulado gobierno brasileño, en circunstancias políticas internas no poco dificultosas, el que desde la Presidencia pro tempore del bloque ha encabezado en el segundo semestre del 2017 el diálogo con Europa, primero en septiembre en Bruselas y luego en octubre en Brasilia. Durante el 2018, las negociaciones continuaron, pero hasta el momento, cuando escribo estas líneas, no ha terminado de confirmarse el acuerdo a pesar de los anuncios que se han hecho, el cual, en caso de aprobarse, será, sin duda, menos ambicioso de lo que se preveía inicialmente. En ese marco, la oferta europea en materia agrícola ha sido muy desalentadora, por lo que se han reducido las expectativas más optimistas respecto a la posibilidad antes manejada de concretar un acuerdo en verdad relevante. En cualquier hipótesis, la posible confirmación del acuerdo comercial con la Unión Europea será sin duda una nueva prueba para evaluar los límites y alcances del cambio de orientación en curso del bloque Mercosur, lo cual dependerá también, por lo demás, de la profundidad y del realismo con el que sigan las negociaciones, en particular por cuanto atañe a la indispensable reformulación de la oferta europea.

Aunque algunas de las situaciones descritas a propósito de la realidad actual del Mercosur podrían abonar a la hipótesis de su disolución más o menos cercana, hay muchas razones para descartarla, pues son muy fuertes los intereses

${ }^{52}$ Cf. G. Rodríguez Gigena, "Un acuerdo comercial Mercosur-China, ¿'es conveniente?", y S. Torres, "Impactos sectoriales en Uruguay de la firma de un Tratado de Libre Comercio entre Mercosur y China", ambos en G. Caetano (coord.), América Latina ante los nuevos desafios de la globalización, Montevideo, Planeta-CEFIR, 2017. 
en juego entre los países socios (en especial, entre Argentina y Brasil) como para experimentar una opción tan cargada de incertidumbres en las actuales circunstancias. Resulta muy obvio, por tanto, que se va hacia otro MERcosur de matices comercialistas, semejante al de sus orígenes en 1991 y con una flexibilización mucho mayor a todos los niveles.

Los resultados de las elecciones presidenciales del 2018 en Brasil abren nuevos interrogantes. Contra todo lo previsto hasta por lo menos algunos meses antes, en la segunda vuelta ocurrida el domingo 28 de octubre, el candidato ultraderechista Jair Bolsonaro (del Partido Social Liberal) se impuso al candidato Fernando Haddad (del Partido de los Trabajadores, sustituto del encarcelado Lula) por 55 a $44 \%$. Tanto en su programa como en su muy agresiva campaña, Bolsonaro habló muy poco de política exterior. Al comienzo dio algunas señales de "neopatriota" y proteccionista, pero al final selló su alianza con el gran capital, asociándose con Paulo Guedes, conocido economista "neoliberal", designado como su futuro Ministro de Hacienda. En sus primeras declaraciones al día siguiente de la segunda vuelta, Guedes confirmó el giro "liberal, aperturista y de énfasis comercial" de las políticas del nuevo gobierno, agregando que en esa dirección "el MERCOSUR no es prioridad".

De todos modos, más allá de la radicalidad de los discursos (en especial, de los cancilleres), con seguridad la celeridad de las concreciones dependerá mucho más de las variaciones de un contexto externo muy difícil e incierto, que de la voluntad política de los Estados parte. Lo que sí parece claro es que los acontecimientos recientes en Brasil han confirmado y acelerado un desenlace cuyo final, al menos en el corto y mediano plazo, habrá de establecer un MERCOSUR que diste no poco del que ha regido durante el último decenio. 


\section{REFERENCIAS BIBLIOGRÁFICAS}

"Arremete Mujica contra países del Mercosur", El Observador, 11 de enero de 2014, en www.elobservadordigital.com

Balassa, Bela A., Teoría de la integración económica, México, Biblioteca Uthea de Economía, 1964.

BALDwin, Richard, "21 ${ }^{\text {st }}$ Century Regionalism: Filling the Gap between $21^{\text {st }}$ Trade and $20^{\text {th }}$ Century Trade Rules", ssRn, abril de 2011, en https://ssrn.com/abstract=1869845

Bhagwati, Jaghdish, Termites in the Trading System: How Preferential Agreements Undermine Free Trade, Oxford, University Press, 2008.

Baier, Scott, Jeffrey Bergstrand y Peter Egger, "El nuevo regionalismo: causas y consecuencias", Integración Ẽ Comercio, 2007, núm. 26, pp. 9-32.

Barbosa, Rubens, "Revolución comercial", El País, 13 de julio de 2014, en http://www.elpais.com.uy/opinion/revolucion-comercial.html

Belém Lopes, Dawisson y Camilo López Burian, "De Rousseff a Temer, o de cómo la política doméstica condiciona la política exterior", en Anabella Busso (comp.), La inserción internacional argentina en una doble transición, Rosario, Universidad Nacional de Rosario-unr Editora, 2018.

Belém Lopes, Dawisson y Camilo López Burian, "La política exterior brasileña del siglo xxi: un cambio epocal”, en Diego Abente Brun y Carlos Gómez Florentín (eds.), Panorama de las Relaciones Internacionales en el Paraguay actual, Asunción del Paraguay, Conacyt-Prociencia-Universidad Nacional de Asunción, 2018, pp. 99-129.

Benzi, Daniele y Marco NAREa, "El regionalismo latinoamericano, más allá de los «pos». El fin del ciclo y los fantasmas globales", Nueva Sociedad, 2018, núm. 275, pp. 106 y 119.

Bernal-Meza, Raúl y Lincoln Bizzozero, La política internacional de Brasil: de la región al mundo, Montevideo, Ediciones Cruz del Sur, 2014.

Bouzas, R., H. Jaguaribe, R. Lavagna, M. Paz Castaing, F. Peña, C. Raimundi, A. Sepúlveda Almarza y A. Volonté Berro, 
"El mercosur a 15 años de su creación", Revista Relaciones Internacionales, sección Diálogos, 15 (2006), núm. 30, pp. 3-23.

Briceño Ruiz, José, "Hegemonía, poshegemonía, neoliberalismo, posneoliberalismo en los debates sobre el regionalismo en América Latina”, en Martha Ardila (ed.), ¿Nuevo multilateralismo en América Latina? Concepciones y actores en pugna, Bogotá, Universidad Externado de Colombia, 2016.

Burges, Sean, "Revisiting Consensual Hegemony: Brazilian Regional Leadership in Question”, International Politics, 52 (2015), pp. 193-207.

Caetano, Gerardo, "El futuro de la integración regional: entre la administración de conflictos y la necesidad de pensamiento estratégico" en Mercosur. Prospectiva 20 años, Montevideo, CeFIR-FESUR, 2012, pp. 19-28.

Caetano, Gerardo (coord.), Mercosur 20 años, Montevideo, Cefir, 2011.

Caetano, Gerardo (coord.), América Latina ante los nuevos desafíos de la globalización, Montevideo, Planeta-CEFIR, 2017.

Caetano, Gerardo e Ignacio BARTESAGHi, "La agenda externa del Mercosur y las negociaciones con la Unión Europea: ¿la última oportunidad?", Aldea Mundo. Revista sobre fronteras e integración, 19 (2014), núm. 37, pp. 9-24.

CÁrdenas, Emilio, "El nuevo decálogo de la política exterior de Brasil”, La Nación, 26 de mayo de 2016, en https://www.lanacion.com.ar/1902513-el-nuevo-decalogo-de-la-politica-exterior-de-brasil

Dosch, Jörn y David S. G. Goodman, "China and Latin America: Complementarity, Competition, and Globalisation", Journal of Current Chinese Affairs, 41 (2012), núm. 1, pp. 3-19.

Facchini, Giovanni, Peri Silva y Gerald Willmann, "The Customs Union Issue: Why do We Observe so Few of Them?”, Journal of International Economics, 90 (2008), núm. 1, pp. 136-147.

Fernández, Pablo S., "Los presidentes del Mercosur se comprometen a revitalizarlo", El País, 22 de julio de 2017, en https:/ / plus.google.com/share?url=http:/ / www.elpais.com.uy/informacion/presidentes-mercosur-se-comprometen-revitalizarlo. html 
Flemes, Daniel, "Brazilian Foreign Policy in the Changing World Order", South African Journal of International Affairs, 16 (2009), núm. 2, pp. 161-182.

Flemes, Daniel y Thorsten Wojczewski, "Contested Leadership in International Relations: Power Politics in South America, South Asia and Sub-Saharan Africa" (GIGA Working paper, 121), sSRN, 4 de febrero de 2010, en https://ssrn.com/abstract=1547773

Flemes, Daniel y Leslie Wehner, "Drivers of Strategic Contestation: The Case of South America", International Politics, 52 (2015), pp. 163-177.

Granovsky, Martín, "Entrevista a Samuel Pinheiro Guimaraes, ex vicecanciller de Lula. «En Brasil hubo una conspiración»", Página 12, 20 de mayo de 2016.

Gratius, Susane (ed.), MerCosUR y NAFTA. Instituciones y mecanismos de decisión en procesos de integración asimétricos, Madrid, Iberoamericana-Vervuert, 2008.

Hipótesis para el Mercosur que viene, Montevideo, CEFIR-FESUR, 2014. Hochstetler, Kathryn, "Multi-Level Governance and Social Movements in Mercosur", ponencia presentada en la 2007 Annual Convention of the American Political Science Association, Chicago, IL, 30 de agosto-2 de septiembre.

Jenkins, Rhys, "China and Brazil: Economic Impacts of a Growing Relationship”, Journal of Current Chinese Affairs, 41 (2012), núm. 1, pp. 21-47.

Jenkins, Rhys, "Chinese Competition and Brazilian Exports of Manufactures”, Oxford Development Studies, 42 (2014), pp. 395-418.

La Alianza del Pacífico y el Mercosur. Hacia la convergencia en la diversidad, Santiago de Chile, Naciones Unidas-CEPAL, 2014.

LANDER, Edgardo, “¿Modelos alternativos de integración? Proyectos neoliberales y resistencias populares", OSAL, 5 (2004), núm. 15, pp. 9-12.

LIRIo, Sergio, "Brasil: el golpe y la geopolítica. Entrevista al Profesor Luis Alberto Moniz Bandeira", AmerSur, 19 de mayo de 2016, en www.amersur.org/tag/luiz-alberto-moniz-bandeira/

Malamud, Andrés, "A Leader without Followers? The Growing Divergence between the Regional and Global Performance of 
Brazilian Foreign Policy”, Latin American Politics and Society, 53 (2011), núm. 3, pp. 1-24.

Malamud, Andrés, "Conceptos, teorías y debates sobre la integración regional”, Norteamérica. Revista Académica del CISAN-UNAM, 6 (2011), núm. 2, pp. 234-236.

Malamud, Andrés y Philippe C. Schmitter, "La experiencia de integración europea y el potencial de integración del MERCOsur”, Desarrollo Económico. Revista de Ciencias Sociales, 46 (2006), núm. 181, pp. 3-31.

Mascarenhas, Pamela, "Celso Amorim: Brasil precisa de novo rumo para reconquistar credibilidade", Jornal do Brasil, 19 de junio de 2016.

Mondelli, Marcelo, "Case Studies on Social Dimension in MercoSUR, ECOWAS and ASEAN", documento de trabajo, Buenos Aires, CLACSO, 2015.

Nepomuceno, Eric, "Brasil y el vuelco radical en su política externa”, La Jornada, 22 de mayo de 2016, en http://www.jornada. com.mx/2016/05/22/opinion/016a2pol

Oliveira, Amâncio Jorge de y Janina Onuki, "Eleições, Partidos Políticos e Política Externa no Brasil”, Revista Política Hoje, 19 (2010), num. 1, pp. 144-185.

Pantojas García, Emilio, "El alca: un inventario de su proceso", Anuario de la Integración Regional de América Latina y el Gran Caribe, 2007, núm. 6, coord. por Andrés Serbin, Pável Isa-Contreras y Lázaro Peña, pp. 37-45.

Perales, José Raúl, "A Supply-Side Theory of International Economic Institutions for the Mercosur", en Finn Laursen (ed.), Comparative Regional Integration: Theoretical Perspectives, Aldershot, Ashgate, 2003.

Pinheiro, Leticia y Gabrieli Gaio, "Cooperation for Development, Brazilian Regional Leadership and Global Protagonism”, Brazilian Political Science Review, 8 (2014), núm. 2, pp. 8-30.

Rodríguez Gigena, Gonzalo, "Un acuerdo comercial MERCosurChina, ¿es conveniente?”, en Gerardo Caetano (coord.), América Latina ante los nuevos desafíos de la globalización, Montevideo, Planeta-CEFIR, 2017. 
Rosamond, Ben, Theories of European Integration, Basingstoke, Macmillan-St. Martin's Press, 2000.

Sbragia, Alberta, "Review Article: Comparative Regionalism: What Might It Be?”, Journal of Common Market Studies, 46 (2008), pp. 29-49.

SANAHUJA, José Antonio, "Del «regionalismo abierto» al «regionalismo post-liberal». Crisis y cambio en la integración regional en América Latina", Anuario de la Integración Regional de América Latina y el Gran Caribe, 2008-2009, núm. 7, coord. por Laneydi Martínez Alfonso, Lázaro Peña y Mariana Vazquez, pp. 11-54.

SanahuJa, José Antonio, "Regionalismo «post-liberal» y multilateralismo en Sudamérica", Anuario de la Integración Regional de América Latina y el Gran Caribe, 2012, núm. 9: El regionalismo "post-liberal" en América Latina y el Caribe: nuevos actores, nuevos temas y nuevos desafios, coord. por A. Serbin, L. Martínez y H. Romanzini Júnior, pp. 19-72.

Sanahuja, José Antonio, "Posglobalización y ascenso de la extrema derecha: crisis de hegemonía y riesgos sistémicos", Anuario CEIPAZ 2016-2017: Seguridad internacional y democracia: guerras, militarización y fronteras, coord. por Manuela Mesa, pp. 41-77.

Sanahuja, José Antonio y Nicolás Comini, "Las nuevas derechas latinoamericanas frente a una globalización en crisis", Nueva Sociedad, 2018, núm. 275, pp. 36-37.

Saraiva, Miriam Gomes, "Brazilian Foreign Policy towards South America during the Lula Administration: Caught between South America and Mercosur", Revista Brasileira de Politica Internacional, 53 (2010), núm. esp., pp. 151-168.

Serbin, Andrés, Laneydi Martínez y Haroldo Romanzini Júnior (coords.), Anuario de la Integración Regional de América Latina y el Gran Caribe, 2012, núm. 9: El regionalismo "post-liberal" en América Latina y el Caribe: nuevos actores, nuevos temas y nuevos desafios.

STRÜVER, Georg, " "Bereft of Friends»? China's Rise and Search for Political Partners in South America”, Chinese Journal of International Politics, 7 (2014), pp. 117-151.

Torres, Sebastián, "Impactos sectoriales en Uruguay de la firma de un Tratado de Libre Comercio entre Mercosur y China", 
en Gerardo Caetano (coord.), América Latina ante los nuevos desafíos de la globalización, Montevideo, Planeta-CEFIR, 2017.

Urdinez, Francisco, "The Political Economy of the Chinese Market Economy Status Given by Argentina and Brazil”, CS, 2014, núm. 14, pp. 47-75.

Urdinez, Francisco, Camilo López Burian y Amâncio Jorge de Oliveira, "Mercosur and the Brazilian Leadership Challenge in the Era of Chinese Growth: A Uruguayan Foreign Policy Perspective”, New Global Studies, 10 (2016), pp. 1-25.

Van Klaveren, Alberto, "El eterno retorno del regionalismo latinoamericano”, Nueva Sociedad, 2018, núm. 275, pp. 70-71.

"Vázquez propuso en Mendoza seis medidas para revitalizar el MERCOSUR", 21 de julio de 2017, en https://www.presidencia. gub.uy/sala-de-medios/audios/audios-breves/vazquez-medidas-revitalizar-mercosur-cumbre-mendoza 